\title{
Occupational Health and Safety Hazards among Workers in Laboratory Animal Research Facilities in Singapore and the Philippines
}

\author{
Bibay $\mathrm{JI}^{1}$, Agapito $\mathrm{JD}^{1}$
}

${ }^{1}$ Faculty of Management and Development Studies, University of the Philippines Open University, Philippines

\section{ABSTRACT}

Introduction: All workers, regardless of occupation are vulnerable to various hazards present at work. This study was carried out to determine the commonly encountered occupational hazard of laboratory animal workers in Singapore and the Philippines. Moreover, to determine the percentage of hazard exposure according to the workers' personal profile, work profile, and frequency of exposure.

Methods: All members of the Association for Laboratory Animal Science of Singapore $(n=150)$ and the Philippines $(n=130)$ were invited in an online survey administered anonymously via email. Only those respondents who fulfilled the inclusion criteria (i.e., 18 years old and above and working in direct contact with animals and its environment) were included in the analysis.

Results: Laboratory animal workers experienced all hazards identified in the laboratory animal facilities. The three most common hazards encountered by workers based on the mean (M) and median (Mdn) number of exposures were animal-related injuries $(M=1.269, M d n=1)$, ergonomics $(M=1.067, M d n=0)$ and sharp-related injuries $(M=$ $0.885, \mathrm{Mdn}=1$ ). There was no significant difference noted between these three hazards when compared to one another. These hazards were consistent regardless of age, gender, education, job, biosafety level of the facility, years of work experience and type of animal exposures.

Conclusion: Laboratory animal workers in Singapore and the Philippines are exposed to various hazards in the workplace. Younger workers, and workers with higher day-to-day exposure to laboratory animals, should be prioritized for information dissemination, training, and supervision.

Key Words: Hazards, Laboratory animal, Occupational health, Safety, Workers

\section{Introduction}

he workplace directly influences the workers in terms of physical, mental, economic, and social wellbeing. At present, more than half of the world's population are members of the workforce; regardless of the industry and occupation, all workers are exposed to the different hazards at the workplace.

DOI: https://doi.org/10.3126/ijosh.v11i3.39765

Conflicts of interest: None

Supporting agencies: None

Date of submission: 24.07.2021

Date of acceptance: 08.09 .2021

Date of publication: 30.09 .2021

\section{Corresponding Author}

Jan Irving A. Bibay, DVM, MIH

University of the Philippines Open University

Los Baños, Laguna, Philippines, 4031

Email: janirving.bibay@upou.edu.ph

Phone: (65) 83885743
It is mandated by the Public Health Service Policy that institutions should provide safety working environments for all personnel working with animals through an effective animal care Occupational Health and Safety Program. ${ }^{1}$ In the laboratory animal research industry, workers that are working in close contact with laboratory animals and its environment (i.e., veterinary staffs, researchers, technicians and other support staffs) can encounter different hazards while performing their duties. This is due to the complexity of the tasks involved, and the possibility of exposure to different sources of hazards. ${ }^{2}$

Laboratory Animal Allergen (LAA), the identified cause of occupational asthma ${ }^{3-5}$ is believed to be the most

\section{cc) (i) (8)}

This journal is licensed under a Creative Commons AttributionNon Commercial 4.0 International License. 
important health hazard in animal research facilities. ${ }^{6,7}$ However, most animal facilities already implemented good engineering, procedural and personal controls. ${ }^{8,9}$ Moreover, there are other hazards identified that can potentially cause health and safety concerns to workers. These hazards include physical hazards like animal bites, sharp injuries and ergonomics; hazards caused by chemicals such as burns and toxicity; infectious hazards like zoonosis; and allergies from different sources other than animals. ${ }^{2}$

To date, not all facilities housing animals are aware of the hazards that can potentially harm their workers. Some animal facility does not have safety personnel to look after the health and safety of their employees. Furthermore, very few study exist on this field and to our knowledge, there are no current data on the exposure of laboratory animal workers to the possible hazards present at work. The limited knowledge in this area resulted in insufficient safety measures and unaddressed health and safety concerns for the workers. Hence, the study was carried out to determine the actual occupational hazard exposures of workers in laboratory animal research facilities in Singapore and the Philippines. The study specifically aimed to identify the commonly encountered occupational health and safety hazards; and to determine the percentage of hazard exposure according to the workers' personal profile, work profile, and frequency of exposure. These could serve as foundations in developing approaches for hazard risk reduction and generating intervention strategies to address the health and safety of workers in the laboratory animal facilities.

\section{Methods}

The study employed a quantitative, descriptive survey research design. The survey was conducted from JuneJuly 2019 to members of laboratory animal association in Singapore and the Philippines.

The data was collected using the Google forms online survey application. All questions and instructions were written in English language. Most of the questions were standard survey questions to determine the respondents' personal and work profiles. The frequency scale used to assess the workers' exposure to potential hazards was modeled after the workplace health and safety survey available online. The questionnaire was pre-tested to 17 respondents prior to the actual survey.

The members of Singapore Association for Laboratory Animal Science (SALAS), and the Philippine
Association for Laboratory Animal Science (PALAS) were the target population to ensure the validity of respondents with regards to exposure to laboratory animals. There were about 150 SALAS members and 130 PALAS members at the time of survey and all were invited to participate. To maintain anonymity of the respondents, a representative from SALAS and PALAS (i.e., President or secretary) was contacted to disseminate the survey link to all their members via email. Only respondents that satisfied the inclusion criteria of the study were included in the final analysis. The inclusion criteria are workers in animal research facilities that are 18 years old and above and working in direct contact with laboratory animals and its environment.

Descriptive, univariate statistical analyses were performed on the data. To better understand the actual exposure of the workers to an occupational hazard, the percentage of hazard exposures in terms of the workers' frequency of exposure and their personal and work profiles was obtained. Regardless of how frequent the workers experienced the hazards (i.e., annually, semi-annually, etc.), it was counted as exposure. Never means that the workers were not exposed to the hazard. The ordinal data for frequency was converted into numbers to identify the most common hazard (i.e., $0=$ Never, $1=$ Annually, 2= Semi-annually, 3= Quarterly, $4=$ Monthly, $5=$ Weekly and $6=$ Daily). Kruskal-Wallis Rank Test was utilized to test for significant difference between hazards after determination of non-normal distribution by Shapiro-Wilk normality test. A post-hoc Dunn's multiple comparisons test was used for pairwise comparison. To account for multiple comparisons, an adjusted $p$ value was used. Mann-Whitney $U$ test was employed to compare two variables. Statistical significance was set at $p<0.05$. All analyses were performed using the GraphPad Prism9 (GraphPad Software, La Jolla, Ca) application.

The National Ethics Committee of the Philippines approved the study. The informed consent was made available in the first part of the survey. Participation in the survey was purely voluntary. No information gathered during the conduct of the survey can be used to trace the responses back to the respondents or to their institutions.

\section{Results}

A total of $108(38.6 \%)$ survey responses were submitted. Four respondents identified themselves with 
no direct animal contact; hence, only 104 responses were analyzed in the study.

Laboratory animal workers daily experienced all possible hazards identified by the Institute of Laboratory Animal Resources. ${ }^{2}$ Table 1 shows that allergy from unknown sources $(4.8 \%)$ was the most commonly experienced hazard daily. This was followed closely by ergonomics and allergy from animals (3.8\%).

The ordinal data for frequency was converted into numbers to determine the mean (M) and median (Mdn) exposure and to identify the most common hazard. Animal-related injuries (ARI) $(M=1.269, M d n=1)$, ergonomics $(M=1.067, M d n=0)$, and sharp-related injuries (SRI) $(M=0.885, M d n=1)$ were the three most common hazards experienced by workers. An M or Mdn of 1 corresponds to a once a year frequency of exposure. There was no significant difference between the three hazards when compared to one another. When data from Singapore and the Philippines were compared, no significant difference in exposure to ARI. Significant differences were noted on exposure to ergonomics $(p=0.0231)$, and SRI $(p=0.0118)$. The percentage of exposure to ergonomics was higher in workers in Singapore compared to the Philippines. The percentage of exposure to SRI, however, was higher in the Philippines (Table 2).

Table 3 shows the hazard exposure based on age, sex and education presented in percentage. Most laboratory animal workers were in the older category (35 years old and above, 53.8\%) compared to younger workers (18- 34 years old; $46.2 \%$ ). Regardless of age, ARI was the most common hazard encountered (72.9\%, $66.1 \%$, young vs old), followed by SRI $(60.4 \%$, $46.4 \%)$, and ergonomics $(60.4 \%, 37.5 \%)$. Younger workers experienced higher rates of experiencing all potential categories of hazards.

The percentage of exposure to the three most common hazards identified in this study was consistently high regardless of sex. ARI $(73.9 \%, 60.0 \%$, female vs male) and SRI $(53.6 \%, 51.4 \%)$ were common in female than male workers. However, ergonomics $(46.4 \%, 51.4 \%)$ was more common in male workers.

In terms of education, all workers from both countries have at least attended secondary education, and most likely hold either a college degree $(49 \%)$ or a postgraduate degree (PGD) $(43.3 \%)$. Workers with both college and PGD were more exposed to ARI (68.6\%, $73.3 \%$ respectively). Exposures to SRI (51\%,
$64.4 \%)$ and ergonomics $(52.9 \%, 40 \%)$ were also high. Meanwhile, ergonomics (62.5\%) was common for workers with secondary education followed by ARI $(50 \%)$. No incidence of SRI was reported on this group.

Table 4 shows the percentage of hazard exposure based on job and years of experience. For job, the column labelled "others" identified themselves as Institutional Animal Care and Use Committee (IACUC) secretary, assistant professor, Ph.D. student, principal investigator, and sales/technical personnel. For this group, SRI and allergy from animals were the most common hazards encountered $(57.1 \%)$ followed by $\mathrm{ARI}$, ergonomics and allergy from unknown sources $(42.9 \%)$. Majority of the respondents were veterinary personnel $(37.5 \%)$ and researchers $(30.8 \%)$. Workers under these groups were more exposed to ARI (82.1\%, 71.9\% respectively) and SRI (69.2\%, 53.1\%). Allergy from animals (51.3\%) was more common than ergonomics $(43.6 \%)$ for veterinary personnel. Veterinary personnel include both veterinarians and veterinary technicians. Meanwhile, operation staffs, which include animal technicians, supervisors and facility managers, were exposed to ergonomics $(61.5 \%)$ more commonly followed by ARI (53.8\%) and SRI $(26.9 \%)$.

The length of work experience varies from less than a year to more than 20 years. In Table 4, "experience" was categorized into two, less ( $<1-5$ years) and more (6 years and above) experienced workers. Regardless of the length of experience, the most common hazards encountered were ARI $(61.2 \%, 76.4 \%$, less vs more experienced), SRI $(57.1 \%, 49.1 \%)$ and ergonomics $(42.9 \%, 52.7 \%)$. Allergy from animals was also common in less experienced compared to more experienced workers $(40.8 \%, 32.7 \%)$. In general, chemical, biological/infectious related hazards, allergies, and others tended to be higher among those with fewer years of experience. Regarding physical hazards, the trend between those with lesser years of experience in comparison with more years of experience was less distinct. The responses indicated that both groups commonly experienced physical hazards, especially those related to ergonomics as well as ARI and SRI.

Table 5 shows that more workers were exposed to more than one ABSL at work (37.5\%). No workers were exposed to animal works with ABSL 4 status. Fifteen of the respondents $(14.4 \%)$ do not know the ABSL of their facility. Most of these workers were from the Philippines (12 out of 15, data not shown). The most 
common hazards encountered by these workers were ARI (80\%) and SRI (66.7\%). Those workers exposed in ABSL 2 developed animal allergies more commonly than other biosafety levels (53.8\%). Meanwhile, those working in ABSL 3 alone had no reported exposure to any forms of allergy. Exposure to Laboratory Acquired Infections (LAI) was also higher in workers from ABSL 2 compared to other biosafety levels. Regardless of the $A B S L$, the most commonly encountered hazard was ARI.

Majority of the workers were exposed to multiple species of animals at work. The most common animals that the workers were exposed to are mice (88.5\%), rats $(67.3 \%)$, and rabbits $(36.5 \%)$ as shown in Table 6. Interestingly, some workers were exposed to uncommon laboratory animals such as invertebrates, bats, hamster, dogs, cats, ruminants, and reptiles (categorized as "Others" in Table 6). Regardless of animal species handled, exposures to the three most common hazards identified in this study were consistent. Those working with fish and frogs were more exposed to animal allergens (50\% and $46.2 \%$ respectively). For non-aquatic animal species, workers exposed to guinea pigs were more prone to developing allergy from animals (44.4\%).

Table 1: Percentage of hazard exposures based on how frequent the workers encountered the hazards at work

\begin{tabular}{|c|c|c|c|c|c|c|c|}
\hline \multirow[b]{2}{*}{ Hazards } & \multicolumn{7}{|c|}{ Exposure (\%) } \\
\hline & Never & Annual & $\begin{array}{l}\text { Semi- } \\
\text { Annual }\end{array}$ & Quarterly & Monthly & Weekly & Daily \\
\hline \multicolumn{8}{|l|}{ Physical } \\
\hline Animal-Related Injuries & 30.8 & 41.3 & 14.4 & 4.8 & 3.8 & 1.9 & 2.9 \\
\hline Ergonomics & 51.9 & 24.0 & 9.6 & 4.8 & 2.9 & 2.9 & 3.8 \\
\hline Sharp-Related Injuries & 47.1 & 33.7 & 10.6 & 3.8 & 2.9 & 1.0 & 1.0 \\
\hline Slip and Fall & 76.9 & 13.5 & 3.8 & 1.9 & 1.0 & 1.0 & 1.9 \\
\hline Noise Related & 90.4 & 2.9 & 1.0 & 1.0 & 2.9 & 1.0 & 1.0 \\
\hline Radiation Exposure & 86.5 & 5.8 & 0.0 & 0.0 & 3.8 & 1.0 & 2.9 \\
\hline Electricity Related & 88.5 & 3.8 & 3.8 & 0.0 & 0.0 & 1.0 & 2.9 \\
\hline Traumatic Injuries & 81.7 & 13.5 & 3.8 & 0.0 & 0.0 & 0.0 & 1.0 \\
\hline \multicolumn{8}{|l|}{ Chemical } \\
\hline Toxicity & 86.5 & 4.8 & 2.9 & 0.0 & 1.9 & 1.9 & 1.9 \\
\hline Burns & 88.5 & 6.7 & 2.9 & 0.0 & 0.0 & 0.0 & 1.9 \\
\hline Explosions, Fire & 95.2 & 1.9 & 1.0 & 0.0 & 0.0 & 0.0 & 1.9 \\
\hline \multicolumn{8}{|l|}{ Biological/Infectious } \\
\hline LAI & 88.5 & 6.7 & 0.0 & 1.0 & 1.0 & 0.0 & 2.9 \\
\hline \multicolumn{8}{|l|}{ Allergy (from) } \\
\hline Animals & 63.5 & 21.2 & 5.8 & 2.9 & 1.0 & 1.9 & 3.8 \\
\hline Chemicals & 87.5 & 6.7 & 0.0 & 1.0 & 1.9 & 0.0 & 2.9 \\
\hline Biologics & 90.4 & 2.9 & 1.9 & 1.0 & 1.0 & 0.0 & 2.9 \\
\hline Unknown Source & 75.0 & 13.5 & 1.9 & 2.9 & 1.9 & 0.0 & 4.8 \\
\hline Others & 93.3 & 4.8 & 1.0 & 0.0 & 0.0 & 0.0 & 1.0 \\
\hline
\end{tabular}

LAl=laboratory-acquired infections

Table 2: Exposures to the three most common hazards between Singapore and the Philippines

\begin{tabular}{lccc}
\hline \multirow{2}{*}{ Hazards } & \multicolumn{2}{c}{ Exposure (\%) } & \multirow{2}{*}{$\mathbf{p}$ value } \\
\cline { 2 - 3 } & Singapore & Philippines & \\
\cline { 2 - 3 } & $\mathbf{n = 6 0}$ & 77.3 & 0.1419 \\
Animal-Related Injuries & 63.3 & 34.1 & 0.0231 \\
Ergonomics & 58.3 & 68.2 & 0.0118 \\
\hline Sharp-Related Injuries & 41.7 & & \\
\hline
\end{tabular}


Table 3: Percentage of hazard exposures based on age, sex and education of workers

\begin{tabular}{|c|c|c|c|c|c|c|c|}
\hline \multirow{3}{*}{ Hazards } & \multicolumn{2}{|r|}{ Age (\%) } & \multicolumn{2}{|c|}{ Sex $(\%)$} & \multicolumn{3}{|c|}{ Education (\%) } \\
\hline & $\begin{array}{l}\text { Younger } \\
\text { (18-34 y.o) }\end{array}$ & $\begin{array}{c}\text { Older } \\
\text { (35 y.o and above) }\end{array}$ & Male & Female & Sec & College & PGD \\
\hline & $n=48$ & $n=56$ & $n=35$ & $n=69$ & $n=8$ & $n=51$ & $n=45$ \\
\hline \multicolumn{8}{|l|}{ Physical } \\
\hline Animal-Related Injuries & 72.9 & 66.1 & 60.0 & 73.9 & 50.0 & 68.6 & 73.3 \\
\hline Ergonomics & 60.4 & 37.5 & 51.4 & 46.4 & 62.5 & 52.9 & 40.0 \\
\hline Sharp-Related Injuries & 60.4 & 46.4 & 51.4 & 53.6 & 0.0 & 51.0 & 64.4 \\
\hline Slip and Fall & 33.3 & 14.3 & 31.4 & 18.8 & 12.5 & 19.6 & 28.9 \\
\hline Noise Related & 16.7 & 5.4 & 8.6 & 11.6 & 0.0 & 13.7 & 8.9 \\
\hline Radiation Exposure & 27.1 & 1.8 & 14.3 & 13.0 & 0.0 & 13.7 & 15.6 \\
\hline Electricity Related & 22.9 & 1.8 & 11.4 & 11.6 & 0.0 & 9.8 & 15.6 \\
\hline Traumatic Injuries & 31.3 & 7.1 & 17.1 & 18.8 & 12.5 & 19.6 & 17.8 \\
\hline \multicolumn{8}{|l|}{ Chemical } \\
\hline Toxicity & 18.8 & 8.9 & 11.4 & 14.5 & 0.0 & 9.8 & 20.0 \\
\hline Burns & 20.8 & 3.6 & 11.4 & 11.6 & 0.0 & 7.8 & 17.8 \\
\hline Explosions, Fire & 12.5 & 0.0 & 2.9 & 5.8 & 0.0 & 2.0 & 8.9 \\
\hline \multicolumn{8}{|l|}{ Biological/Infectious } \\
\hline LAI & 12.5 & 10.7 & 5.7 & 14.5 & 0.0 & 5.9 & 20.0 \\
\hline \multicolumn{8}{|l|}{ Allergy (from) } \\
\hline Animals & 43.8 & 30.4 & 40.0 & 34.8 & 0.0 & 29.4 & 51.1 \\
\hline Chemicals & 16.7 & 8.9 & 14.3 & 11.6 & 12.5 & 2.0 & 24.4 \\
\hline Biologics & 12.5 & 7.1 & 8.6 & 10.1 & 0.0 & 2.0 & 20.0 \\
\hline Unknown Source & 33.3 & 16.1 & 28.6 & 23.2 & 12.5 & 21.6 & 31.1 \\
\hline Others & 10.4 & 3.6 & 2.9 & 8.7 & 0.0 & 7.8 & 6.7 \\
\hline
\end{tabular}

y.o= years old, $\mathrm{Sec}=$ secondary, $\mathrm{PGD}=$ post-graduate degree, $\mathrm{LAl}=$ laboratory-acquired infections

Table 4: Percentage of hazard exposures based on job and experience of workers

\begin{tabular}{|c|c|c|c|c|c|c|}
\hline \multirow{3}{*}{ Hazards } & \multicolumn{4}{|c|}{ Job (\%) } & \multicolumn{2}{|c|}{ Experience (\%) } \\
\hline & Vet Per & Ops Stf & Res & Others & Less & More \\
\hline & $n=39$ & $n=26$ & $n=32$ & $n=7$ & $n=49$ & $n=55$ \\
\hline \multicolumn{7}{|l|}{ Physical } \\
\hline Animal-Related Injuries & 82.1 & 53.8 & 71.9 & 42.9 & 61.2 & 76.4 \\
\hline Ergonomics & 43.6 & 61.5 & 43.8 & 42.9 & 42.9 & 52.7 \\
\hline Sharp-Related Injuries & 69.2 & 26.9 & 53.1 & 57.1 & 57.1 & 49.1 \\
\hline Slip and Fall & 30.8 & 15.4 & 18.8 & 14.3 & 24.5 & 21.8 \\
\hline Noise Related & 15.4 & 3.8 & 9.4 & 14.3 & 10.2 & 10.9 \\
\hline Radiation Exposure & 17.9 & 11.5 & 9.4 & 14.3 & 22.4 & 5.5 \\
\hline Electricity Related & 17.9 & 3.8 & 9.4 & 14.3 & 20.4 & 3.6 \\
\hline Traumatic Injuries & 17.9 & 19.2 & 18.8 & 14.3 & 22.4 & 16.4 \\
\hline \multicolumn{7}{|l|}{ Chemical } \\
\hline Toxicity & 17.9 & 7.7 & 9.4 & 28.6 & 20.4 & 7.3 \\
\hline Burns & 10.3 & 3.8 & 12.5 & 28.6 & 14.3 & 9.1 \\
\hline Explosions, Fire & 5.1 & 0.0 & 6.3 & 14.3 & 10.2 & 0.0 \\
\hline \multicolumn{7}{|l|}{ Biological/Infectious } \\
\hline LAI & 15.4 & 0.0 & 12.5 & 28.6 & 16.3 & 7.3 \\
\hline
\end{tabular}




\begin{tabular}{lcccccc} 
Allergy (from) & & & & & \\
Animals & 51.3 & 15.4 & 31.3 & 57.1 & 40.8 & 32.7 \\
Chemicals & 17.9 & 3.8 & 9.4 & 28.6 & 16.3 & 9.1 \\
Biologics & 17.9 & 0.0 & 3.1 & 28.6 & 14.3 & 5.5 \\
Unknown Source & 38.5 & 7.7 & 18.8 & 42.9 & 32.7 & 18.2 \\
Others & 12.8 & 0.0 & 6.3 & 0.0 & 8.2 & 5.5 \\
\hline
\end{tabular}

Vet Per=veterinary personnel (veterinarians, veterinary technicians), Ops Stf= operation staffs (animal technicians, supervisors, facility managers), Res=researcher, Others= IACUC secretariat, assistant professor, Ph.D. student, principal investigator, sales, and technical personnel, Less $=$ less than 1 to 5 years of work experience, More $=6$ years and above of work experience, LAI= laboratory-acquired infections

Table 5: Percentage of hazard exposures based on animal biosafety level of the facility

\begin{tabular}{|c|c|c|c|c|c|}
\hline \multirow{3}{*}{ Hazards } & \multicolumn{5}{|c|}{ Exposure (\%) } \\
\hline & ABSL 1 & ABSL 2 & ABSL 3 & Comb & Dnk \\
\hline & $n=22$ & $n=26$ & $n=2$ & $n=39$ & $n=15$ \\
\hline \multicolumn{6}{|l|}{ Physical } \\
\hline Animal-Related Injuries & 54.5 & 65.4 & 100 & 74.4 & 80.0 \\
\hline Ergonomics & 45.5 & 50.0 & 0.0 & 56.4 & 33.3 \\
\hline Sharp-Related Injuries & 40.9 & 61.5 & 100 & 46.2 & 66.7 \\
\hline Slip and Fall & 18.2 & 26.9 & 0.0 & 20.5 & 33.3 \\
\hline Noise Related & 4.5 & 11.5 & 50.0 & 7.7 & 20.0 \\
\hline Radiation Exposure & 9.1 & 11.5 & 0.0 & 17.9 & 13.3 \\
\hline Electricity Related & 9.1 & 15.4 & 0.0 & 10.3 & 13.3 \\
\hline Traumatic Injuries & 9.1 & 15.4 & 0.0 & 25.6 & 20.0 \\
\hline \multicolumn{6}{|l|}{ Chemical } \\
\hline Toxicity & 9.1 & 15.4 & 0.0 & 10.3 & 26.7 \\
\hline Burns & 4.5 & 11.5 & 0.0 & 12.8 & 20.0 \\
\hline Explosions, Fire & 0.0 & 7.7 & 0.0 & 5.1 & 6.7 \\
\hline \multicolumn{6}{|l|}{ Biological//nfectious } \\
\hline LAI & 4.5 & 23.1 & 0.0 & 5.1 & 20.0 \\
\hline \multicolumn{6}{|l|}{ Allergy (from) } \\
\hline Animals & 36.4 & 53.8 & 0.0 & 25.6 & 40.0 \\
\hline Chemicals & 9.1 & 15.4 & 0.0 & 10.3 & 20.0 \\
\hline Biologics & 9.1 & 11.5 & 0.0 & 7.7 & 13.3 \\
\hline Unknown Source & 18.2 & 30.8 & 0.0 & 23.1 & 33.3 \\
\hline Others & 9.1 & 11.5 & 0.0 & 5.1 & 0.0 \\
\hline
\end{tabular}

$\mathrm{ABSL}=$ animal biosafety level, $\mathrm{ABSL} 1=$ involves agents not known to cause disease in healthy humans, ABSL $2=$ involves agents associated with human disease and can cause moderate hazards, ABSL $3=$ involves agents that can cause serious and potentially lethal infections, Comb= combination of 2 or more ABSL, Dnk= do not know, LAl= laboratory-acquired infections

Table 6: Percentage of hazard exposures based on animal contact at work

\begin{tabular}{|c|c|c|c|c|c|c|c|c|c|}
\hline \multirow{3}{*}{ Hazards } & \multicolumn{9}{|c|}{ Exposure (\%) } \\
\hline & Mouse & Rat & GP & Rabbit & NHP & Pig & Fish & Frog & Others \\
\hline & $n=92$ & $n=70$ & $n=9$ & $\mathrm{n}=38$ & $n=25$ & $n=30$ & $n=18$ & $n=13$ & $\mathrm{n}=\mathbf{2 2}$ \\
\hline \multicolumn{10}{|l|}{ Physical } \\
\hline Animal-Related Injuries & 72.8 & 80.0 & 88.9 & 78.9 & 72.0 & 70.0 & 94.4 & 84.6 & 72.7 \\
\hline Ergonomics & 51.1 & 47.1 & 44.4 & 42.1 & 48.0 & 46.7 & 61.1 & 53.8 & 31.8 \\
\hline Sharp-Related Injuries & 53.3 & 54.3 & 77.8 & 60.5 & 56.0 & 66.7 & 72.2 & 61.5 & 72.7 \\
\hline Slip and Fall & 22.8 & 22.9 & 11.1 & 28.9 & 28.0 & 33.3 & 33.3 & 30.8 & 31.8 \\
\hline Noise Related & 10.9 & 12.9 & 22.2 & 10.5 & 16.0 & 13.3 & 27.8 & 30.8 & 22.7 \\
\hline
\end{tabular}


Occupational Health and Safety Hazards among Workers in Laboratory Animal Research Facilities in ...

\begin{tabular}{|c|c|c|c|c|c|c|c|c|c|}
\hline Radiation Exposure & 12.0 & 12.9 & 22.2 & 13.2 & 12.0 & 16.7 & 16.7 & 23.1 & 4.5 \\
\hline Electricity Related & 9.8 & 10.0 & 22.2 & 13.2 & 4.0 & 16.7 & 22.2 & 30.8 & 22.7 \\
\hline Traumatic Injuries & 19.6 & 20.0 & 44.4 & 23.7 & 16.0 & 13.3 & 33.3 & 38.5 & 31.8 \\
\hline \multicolumn{10}{|l|}{ Chemical } \\
\hline Toxicity & 13.0 & 10.0 & 11.1 & 10.5 & 8.0 & 13.3 & 22.2 & 23.1 & 0.0 \\
\hline Burns & 12.0 & 12.9 & 11.1 & 13.2 & 4.0 & 6.7 & 27.8 & 30.8 & 9.1 \\
\hline Explosions, Fire & 4.3 & 4.3 & 0.0 & 2.6 & 0.0 & 3.3 & 11.1 & 15.4 & 0.0 \\
\hline \multicolumn{10}{|l|}{ Biological/Infectious } \\
\hline LAI & 9.8 & 8.6 & 33.3 & 10.5 & 4.0 & 20.0 & 11.1 & 15.4 & 13.6 \\
\hline \multicolumn{10}{|l|}{ Allergy (from) } \\
\hline Animals & 38.0 & 34.3 & 44.4 & 39.5 & 32.0 & 40.0 & 50.0 & 46.2 & 18.2 \\
\hline Chemicals & 12.0 & 10.0 & 33.3 & 10.5 & 4.0 & 16.7 & 22.2 & 30.8 & 4.5 \\
\hline Biologics & 9.8 & 5.7 & 22.2 & 7.9 & 0.0 & 13.3 & 16.7 & 23.1 & 4.5 \\
\hline Unknown Source & 22.8 & 20.0 & 11.1 & 21.1 & 16.0 & 20.0 & 44.4 & 53.8 & 36.4 \\
\hline Others & 6.5 & 8.6 & 11.1 & 5.3 & 8.0 & 10.0 & 16.7 & 15.4 & 18.2 \\
\hline
\end{tabular}

$\mathrm{GP}=$ guinea pig, NHP= non-human primates, Others= invertebrates, bats, hamster, dogs, cats, ruminants, and reptiles, LAl= laboratory-acquired infections

\section{Discussions}

The three most common hazards identified were consistent regardless of the personal and work profiles of the workers. According to the Management of Animal Care and Use Programs in Research, Education and Testing, the majority of injuries reported from animal care facilities are related to ergonomics, mostly musculoskeletal traumas. Injuries caused by animals are preventable but always present in the laboratory animal environment. Sharp objects can be found throughout the facility and can potentially cause traumatic tissue injuries. ${ }^{10}$

Younger workers experienced higher frequencies of experiencing all potential hazards compared to older workers. This finding is consistent with the information from the Young Worker Safety and Health, where younger workers, in general, tend to encounter higher rates of injuries in the workplace. ${ }^{11}$ This is because younger workers generally have lesser experience in doing tasks, and require greater supervision. Moreover, they are also more likely to have inadequate safety training exposures or may still lack awareness about workplace responsibilities.

In the previous study on workers in a gender-segregated workplace, a greater share of women was reported to experience musculoskeletal symptoms as compared to men. This was ascribed to the fact that women tended to perform more repetitive works as compared to men in a male dominated workplaces. ${ }^{12}$ In laboratory animal settings, there is usually no segregation of works between the two genders. However, in most circumstances, males tend to perform tasks that require lifting and moving of heavy objects.

Workers with either college or PGD represented jobs that require frequent contact with animals such as veterinary personnel and researchers. These groups have higher chances of acquiring ARI. Veterinary personnel can be exposed to animal injuries during veterinary care and treatment. Researchers were exposed during experimental procedures. Potential sources of sharp injuries for veterinary personnel are needles from the use of injections when dispensing, and administering medications. For researchers, the use of needles and lancets are common during experimental procedures. Meanwhile, ergonomics was found to be common for workers that obtained secondary education. These workers belonged to operation staffs. Workers in this group were involved in tasks such as cage changing, lifting, pulling, and pushing of heavy objects like trolley of cages and feedbags and carrying animals. These activities requiring repetitive movements are the usual causes and contributing factors of ergonomics for laboratory animal workers. ${ }^{13,14}$

Another remarkable finding in this study is that more experienced workers had higher exposures to ARI and ergonomics compared to less experienced workers. This can be attributed to more animal exposures on their career. Less experienced workers on the other hand had higher percentage of exposure to animal allergens. In line with the result of the study on apprentices exposed to laboratory animals, sensitization, symptoms, and 
disease caused by animal allergen occur maximally in the first two to three years after starting exposure to laboratory animals. ${ }^{15}$

The absence of exposure to different forms of allergies, chemical related hazards and LAI for those working in ABSL 3 could be ascribed to more stringent measures required on this biosafety level. The use of PPE is more stringent in ABSL 3 facilities and access to this level is limited to certified personnel due to potential zoonotic agents involved. ${ }^{13}$ Meanwhile, those working in ABSL 2 were more exposed to LAl. This is in agreement to the findings of previous study. ${ }^{16}$ Laboratory animals are potential hosts to a variety of zoonotic pathogens. Cases of human infections were documented in animal research setting, some of which can be lifethreatening. ${ }^{17}$ The common pathogens associated with LAI include Dengue virus, Mycobacterium spp., Shigella spp, Brucella spp and Rickettsia spp. Workplaces with these pathogens were either ABSL 2 or $3 .{ }^{18}$ Hence, the higher prevalence of $L A I$ in $A B S L 2$ facilities can be attributed to the pathogens involved in this biosafety level.

Exposure to multiple species of animals is common for laboratory animal workers. Regardless of the species of animals handled, exposure to the common hazards identified in this study was consistently high. Moreover, exposure to animal allergen was observed regardless of animals handled in the laboratory. The highest percentage of exposure to animal allergen was noted on workers handling aquatic animals such as fish and frogs. This is supported by a previous study, proving fish has allergens that can potentially cause allergies to humans. ${ }^{19}$ For non-aquatic animal species, workers exposed to guinea pigs were more prone to developing allergies from animals. This result ties well with the epidemiological study of laboratory animal workers in
Japan that reported the highest prevalence of LAA in workers exposed to guinea pigs as compared to other laboratory animals. ${ }^{20}$

\section{Limitations}

The study was strictly bounded by ethics; hence it was susceptible to nonresponse bias. To address this limitation, the survey questionnaire was designed to minimize the subjectivity and time necessary for completing the survey. A reminder email was also sent to the participants' midway of the data collection. Additionally, a random sampling technique was not utilized in this study. Therefore, the study was unable to perform correlation analysis between variables.

\section{Conclusion}

Based on the findings, laboratory animal workers in Singapore and the Philippines are exposed to different hazards in the workplace. The three most common hazards identified namely animal-related injuries; sharp-related injuries and ergonomics were consistent regardless of the personal, and work profiles of the workers. Younger workers, and workers with higher day-to-day exposure to laboratory animals, should be prioritized for information dissemination, training, and supervision. In this manner, their awareness, and skills to minimize the occurrence of work-related hazards are strengthened.

\section{Acknowledgements}

The authors would like to thank Dr. Jingky Kühne, Dr. Raymundo Celestino Habito Jr., Dr. Caridad Ancheta and Dr. Romeo Villarta for sharing their expertise. The authors also gratefully acknowledge Dr. Chrisma Domingo and Dr. Melissa Rondina for the support during the survey.

\section{References}

1. Goodly LJ, Jarrell VL, Miller MA, Banks MC, Anderson TJ, Branson KA, et al. Developing a Comprehensive Animal Care Occupational Health and Safety Program at a Land-Grant Institution. J Am Assoc Lab Anim Sci. 2016.55(1):50-7.

2. Institute of Laboratory Animal Resources (U.S.), editor. Occupational health and safety in the care and use of research animals. Washington, DC: National Academy Press; 1997. 154 p. Available from : https://

www.nap.edu/catalog/4988/occupational-healthand-safety-in-the-care-and-use-of-research-animals

3. Acton D, McCauley L. Laboratory Animal Allergy: An Occupational Hazard. AAOHN Journal; Thorofare. 2007.55(6):241-4.

4. Elliott L. Incidence of allergy and asthma among workers exposed to laboratory animals [Internet] [Ph.D.]. [United States -- North Carolina]: The University of North Carolina at Chapel Hill; 2004 [cited 2017 Oct 7]. Available from: https:// 
search.proquest.com/docview/305168666/abstract/ B9A142D793954D7FPQ/2

5. Muzembo BA, Eitoku M, Inaoka Y, Oogiku M, Kawakubo $M$, Tai R, et al. Prevalence of Occupational Allergy in Medical Researchers Exposed to Laboratory Animals. Ind Health. 2014.52(3):256-61.

6. Jones M. Laboratory Animal Allergy in the Modern Era. Current Allergy and Asthma Reports; Philadelphia. 2015.15(12):1-8.

7. Kampitak T, Betschel SD. Anaphylaxis in laboratory workers because of rodent handling: two case reports. 2016.58(4):381-3

8. Feary JR, Schofield SJ, Canizales J, Fitzgerald B, Potts $\mathrm{J}$, Jones $\mathrm{M}$, et al. Laboratory animal allergy is preventable in modern research facilities. Eur Respir J. 2019. 53(6):170-91.

9. Gordon S, Preece R. Prevention of laboratory animal allergy. Occupational Medicine; Oxford. 2003. 53(6):371-7

10. Schmitt JM, Wilson DE, Raber JM. Occupational Safety and Health. In: Weichbrod RH, Thompson GA (Heidbrink), Norton JN, editors. Management of Animal Care and Use Programs in Research, Education, and Testing [Internet]. 2nd ed. Boca Raton (FL): CRC Press/ Taylor \& Francis; 2018 [cited 2021 Jul 24]. Available from: http://www.ncbi.nlm.nih.gov/books/NBK500440/

11. Young Worker Safety and Health | NIOSH | CDC [Internet]. 2020 [cited 2021 Jul 22]. Available from: https://www.cdc.gov/niosh/topics/youth/default.html

12. Karlqvist L. Ergonomic Conditions and Health at Gender Segregated Workplaces. The Ergonomics Open Journal. 2012.5(1):19-27.
13. Fridland G, editor. LATG Laboratory Animal Technologist Training Manual Workbook. AALAS; 2008. 131 p. Available from : https://ncifrederick.cancer.gov/ scientificlibrary/electronicresources/Aalas.aspx

14. Kerst J. An ergonomics process for the care and use of research animals. ILAR Journal. 2003;44(1):3-12.

15. Gautrin D, Ghezzo H, Infante-Rivard C, Malo J-L. Natural history of sensitization, symptoms and occupational diseases in apprentices exposed to laboratory animals. European Respiratory Journal. 2001:17(5):904-8.

16. Li XY, Xue KN, Jiang JS, Lu XC. The Main Biological Hazards in Animal Biosafety Level 2 Facilities and Strategies for Control. Biomedical and Environmental Sciences. 2016. 29(4):300-4.

17. Hankenson FC, Johnston NA, Weigler BJ, Di Giacomo RF. Zoonoses of occupational health importance in contemporary laboratory animal research. Comparative Medicine. 2003.53(6):579-601.

18. Siengsanan-Lamont J, Blacksell SD. A Review of Laboratory-Acquired Infections in the Asia-Pacific: Understanding Risk and the Need for Improved Biosafety for Veterinary and Zoonotic Diseases. Trop Med Infect Dis [Internet]. 2018 Mar 26 [cited 2019 Jul 26];3(2). Available from: https://www.ncbi.nlm.nih.gov/ pmc/articles/PMC6073996/

19. Hilger $C$, van Hage M, Kuehn A. Diagnosis of Allergy to Mammals and Fish: Cross-Reactive vs. Specific Markers. Curr Allergy Asthma Rep. 2017.17(9):64.

20. Aoyama K, Ueda A, Manda F, Matsushita T, Ueda T, Yamauchi C. Allergy to laboratory animals: an epidemiological study. Br J Ind Med. 1992.49(1):41-7. 